\title{
USO DA PAPAÍNA NA ÚLCERA PLANTAR 1
}

THE USE OF PAPAINE ON PLANTAR ULCERS

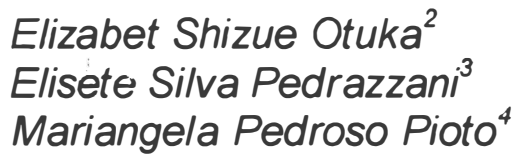

RESUMO: Este trabalho teve por objetivo contribuir para a diminuição da incapacidade em hanseníase e as contínuas recidivas de úceras plantares, através da utilização de um método de tratamento com o uso da papaína e ações de educação em saúde. Foi realizado em um Centro de Saúde com pacientes que apresentavam úcera plantar e que concordaram em participar do tratamento proposto. Analisando e comparando os dados obtidos antes e após o tratamento, concluímos que durante o tratamento foi observada uma maior adesão dos pacientes ao mesmo, uma cicatrização mais rápida em relação a outros métodos utilizados anteriormente e uma maior interação com 0 paciente.

UNITERMOS: Hanseníase - Úlcera plantar.

\section{INTRODUÇÃO}

Segundo Torehinsk, in Cristofolini (1983) a sensibilidade dolorosa, térmica, constitui a maior defesa e proteção contra agressões e traumatismos do pé. A alteração da sensibilidade protetora, associada, muitas vezes, a deformidades do pé por transtornos motores e traumatismos mecânicos constantes, favorecido por um calçado inadequado, produzirão hiperqueratoses, fissuras, escoriações, bolhas e erosões.

Pequenas ações traumáticas desapercebidas ao atuar numa área insensivel, junto com um apoio vicioso, podem levar à úlcera.

O aparecimento da úlcera plantar é o clímax de uma série de mudanças na mecânica que protege o pé contra traumatismos, durante o "stress" da marcha (Prince in Cristofolini, 1983), sendo que estas, no doente de hanseniase, se instalam sobre proeminências ósseas em locais bem definidos (Cristofolini, 1983).

As recidivas e complicações que levam a repetidos e prolongados transtornos ao paciente hanseniano são decorrentes na maioria das vezes de conhecimentos falhos e práticas de cuidados incorretos com os pés insensíveis.

\footnotetext{
${ }^{1}$ Trabalho desenvolvido com bolsista de extensão.

2 Aluna do Curso de Graduação em Enfermagem da UFSCAR.

${ }^{3}$ Enfermeira, Professora Doutora de Enfermagem da UFSCAR.

${ }^{4}$ Fisioterapeuta do Ambulatório Regional de Especialidades de São Carlos -SP.
} 
Muitos fatores podem interferir na exata aplicação dos cuidados preventivos. A falta de uma orientação sistemática clara e convincente, que leva o indivíduo à mudança de atitudes em relação ao problema, e a ausência de supervisão são os principais motivos das falhas existentes (Ross in Cristofolini, (1983).

A cronicidade do problema exige que os cuidados sejam aplicados todos os dias, de maneira constante e persistente. Isto faz com que muitos pacientes abandonem o tratamento vencidos pelo desânimo e descrédito pela lentidão dos resultados. Certas necessidades de locomoção, trabalho e outras ordens sócio-econômicas fazem com que deixem de aplicar certos cuidados, motivando reincidências de úlceras já cicatrizadas, (Cristofolini, 1983).

A detecção precoce, a prevenção e a reabilitação das incapacidades são fundamentais para o controle da hanseniase, entretanto o indivíduo com perda da sensibilidade plantar está propenso a ter uma úlcera plantar, pois há o risco de lesões devido à exposição.

Se as medidas preventivas evitando o aparecimento da úlcera não forem eficazes, faz-se necessário a adoção de determinadas condutas intervencionistas de forma a contribuir para a cicatrização da mesma.

Segundo Monetta (1990), atualmente, o debridamento com enzimas proteolíticas tem sido proposto para obter-se uma rápida remoção, não traumática, do material protéico não desejável nas lesões, apresentando a vantagem de não oferecer nenhum risco ao paciente. A utilização da papaína como enzima proteolítica intervém de forma a acelerar o processo de cicatrização, desinflamando o local; com a utilização da papaina, existe um alinhamento das fibras que compõem o colágeno, e conseqüentemente haverá um crescimento tecidual uniforme com um produto cicatricial mais plano. A cicatrização da lesão ocorre em concomitância a outros procedimentos que necessitam de serem adotados pelo paciente como: repouso do membro e a seqüência do tratamento.

Nos países subdesenvolvidos, o uso da tecnologia importada e a falta de tecnologia adequada aos problemas de saúde locais fazem com que o foco de atenção se desloque para os agravos à saúde, característicos das áreas desenvolvidas, em detrimento de doenças como a tuberculose, a malária, a hanseniase, que se mantêm prevalentes no mundo subdesenvolvido, mesmo nos grandes centros urbanos. Em conseqüência, não só a população em geral, mas também os profissionais de saúde se surpreendem quando informamos sobre o número de mortes causadas pela malária ou o número de incapacitados físicos e sociais por doenças como a hanseníase (Organização Pan-americana de Saúde, 1983).

A prevalência de pacientes com comprometimento continua a aumentar progressivamente. A incidência de incapacidade diminui muito pouco, de forma que o número de pacientes que requerem controle de incapacidades é ainda muito grande, (Trindade e Nemes, 1992).

Preocupados com a questão das incapacidades causadas pela hanseníase, - presente trabalho foi proposto visando a utilização de um método de tratamento com o uso da papaína e também a realização de orientações adequadas aos novos hábitos a que o paciente terá que se submeter para prevenir as recidivas. 
É importante destacar que este programa de atendimento com o uso da papaína vem sendo desenvolvido por profissionais da enfermagem (enfermeiras e a estagiária do curso de graduação em enfermagem) e com o apoio da equipe de saúde local.

O presente trabalho teve por objetivo:

- Identificar os pacientes com úlcera plantar.

- Contribuir para a diminuição da incapacidade em hanseníase e as contínuas recidivas de úlceras plantares.

- Padronizar a técnica de curativo em úlceras plantares com o uso da papaína na unidade de saúde.

- Orientar o paciente e a família sobre o uso da técnica no domicílio.

\section{METODOLOGIA}

\section{Local}

Este trabalho vem sendo desenvolvido na área de Dermatologia Sanitária do Ambulatório Regional de Especialidades do município de São Carlos, pertencente à Direção Regional de Saúde de Araraquara (Dir 7), localizada na região central do Estado de São Paulo.

\section{População}

Pacientes que apresentavam úlcera plantar e que se interessavam em participar do tratamento proposto.

\section{Procedimentos}

Para o desenvolvimento do estudo foram realizados as seguintes etapas:

1) Levantamento dos prontuários para a identificação dos pacientes.

2) Levantamento bibliográfico para a padronização do procedimento.

3) Elaboração de formulários para registro e acompanhamento dos casos (Anexos 1 e 2).

4) Aquisição dos materiais necessários ao desenvolvimento da técnica(utiliza-se a papaína em pó 1:750).

5)Convocação dos pacientes.

6) Esclarecimento ao paciente sobre o procedimento para a realização do tratamento e sua aceitação para posterior inclusão no programa.

Utilizou-se a técnica padronizada por Monetta (1990); com realização diária do curativo e nos fins de semana o mesmo vem sendo realizado pelo próprio paciente, em casa, quando possivel; para isto realizou-se visita domiciliar, de forma a identificar as condições mínimas para a sua realização (fornecendo-se todo o material necessário) ou orientando para realizar apenas a higiene com água e sabão. 


\section{RESULTADOS}

Apresentamos a seguir a descrição de três casos atendidos na unidade de saúde.

\section{CASO 1 -}

Nome: EGC Sexo: $M$ Idade: 69 anos

Forma clínica: $V \quad$ Alta por cura: $17 / 03 / 94$

Aparecimento da primeira úlcera: 06/08/79 com várias recidivas.

Grau de Incapacidade: III

Início do tratamento com papaína: 02/03/95

Aspecto inicial da úlcera: Calosidades e sangramento num total de 5 úlceras.

Localização: As úlceras plantares localizavam-se na região entre $04^{\circ}$ e $5^{\circ}$ metatarsianos no pé $E$ e cabeça do $5^{\circ}$ metatarsianos e cabeça $1^{\circ}$ metatarsianos pé $D$.

Foi colocado barra metatarsiana nos dois calçados.

Foi realizado hidratação e retirada de calosidades e posteriormente o curativo.

Início da cicatrização: $29 / 03 / 95$, no $20^{\circ}$ dia do tratamento.

Paciente permaneceu ausente do serviço por 22 dias.

Reinício do tratamento em 17/05/95, quando foi reforçada a importância dos cuidados com os pés e dada a seqüência do tratamento, sendo confeccionado palmilhas.

Este paciente não apresenta condições para realização do curativo no domicílio nos fins de semana, tendo sido orientado para realizar apenas a higiene com água e sabão.

Notamos uma nova fase de cicatrização no $68^{\circ}$ dia de curativo.

Verificamos que este paciente cuida pouco de sua aparência pessoal e higiene, o que dificulta a incorporação de medidas mais concretas dos cuidados orientados. Atualmente apresenta apenas uma lesão no pé $D$ e uma no pé $E$, sendo que esta ultima tem sinais de infecção.

O paciente foi encaminhado a um Centro de Referência para avaliação médica e posterior confecção dos calçados, e com isto esperamos que ocorra um efetivo processo de cicatrização das úlceras plantares.

\section{CASO 2 -}

Nome: MAS Sexo: $F \quad$ Idade: 47 anos

Forma clínica: I Alta por cura: $6 / 4 / 88$.

Aparecimento da úlcera: há 16 anos.

Grau de incapacidade: II

Início do tratamento com papaína: 23/03/95.

Aspecto inicial das úlceras: Odor forte, com grande quantidade de secreção, uma medindo aproximadamente $6 \times 5,5 \mathrm{~cm}$ e a lesão menor $4 \times 2,8 \mathrm{~cm}$, nos pontos extremos. 
Localização das úlceras: Região antero-interna do pé $D$, ao nível do tornozelo.

Esta paciente mostrou-se interessada em contribuir no seu tratamento e portanto foi treinada para realizar o curativo no domicílio, nos fins de semana; durante $o$ atendimento diário na unidade de saúde, tem uma participação ativa na realização dos mesmos. Em alguns períodos do tratamento a paciente apresentou um processo de infecção na lesão e, em discussão com o médico da área, optou-se por associar o uso do açúcar na realização da técnica do curativo. Paciente apresenta "problema vascular" e vem sendo acompanhada por especialista. Vale ressaltar que, por prescrição médica, a paciente fez uso de penicilina $G$ benzatina, 1200 unidades a cada 10 dias.

Atualmente, no $68^{\circ}$ dia de tratamento, observamos diminuição da lesão, e esta encontra-se com características de cicatrização, com medidas inferiores às do início do programa de atendimento, sendo a lesão maior com $5,5 \times 4,5 \mathrm{~cm}$ e a menor com $3,5 \times 2 \mathrm{~cm}$ em seus extremos; observamos também que a profundidade da úlcera é menor em relação ao início do tratamento.

CASO 3 -

Nome: VS Sexo: M Idade: 70 anos

Forma clínica: $V \quad$ Alta: Paciente permanece em tratamento (PQT).

Grau de incapacidade: II

Início da úlcera plantar: 10/08/94, com recidivas.

Aspecto inicial da úlcera: limpa, com calosidade, sem sinais de infecção.

Localização: cabeça do $1^{\circ}$ metatarsiano do pé E.

Início do tratamento com papaína: 29/05/95

Foram confeccionadas palmilhas para ambos os pés.

Este paciente mostrou-se bastante regular no tratamento e apesar de ter demonstrado grande empenho no seu tratamento observamos uma boa evolução na cicatrização da úlcera e sendo assim optamos para que o mesmo realizasse apenas a higiene da lesão com água e sabão nos finais de semana.

Após $\circ 18^{\circ}$ dia de curativo observa-se fase final de cicatrização, com fechamento completo da úlcera.

Com a fase final de cicatrização, o paciente foi agendado semanalmente para avaliação e acompanhamento das orientações dadas; atualmente é mantido com agendamento quinzenal, sendo reforçadas as condutas de hidratação, retirada da calosidade, lubrificação dos membros inferiores e manutenção do uso das palmilhas.

Ao desenvolver o programa de atendimento, notamos que os pacientes com úlcera plantar conheciam os cuidados preventivos e a falta de orientação clara e convivente leva o indivíduo a não mudar suas atividades em relação ao problema. 
Evidenciamos existir falhas nos portadores de úlcera plantar em relação a tomar condutas adequadas e falta de outras medidas terapêuticas para o processo de cicatrização das úlceras.

Destacamos ainda que o desenvolvimento deste programa foi possível por contarmos com a participação de uma aluna do curso de Graduação em Enfermagem como Bolsista de Extensão.

\section{CONSIDERAÇÕES FINAIS}

Embora o número de casos acompanhados no programa de atendimento seja reduzido, consideramos importante destacar que, tendo-se analisado e comparado os dados obtidos antes e após o tratamento, observamos que:

- Os pacientes portadores de hanseniase com úlcera plantar que participaram do tratamento obtiveram uma cicatrização mais rápida ou evoluiu o processo de cicatrização da úlcera.

- A papaína é de grande auxílio no tratamento da úlcera plantar .

- A técnica para realização do curativo é simples, podendo ser facilmente aprendida pelo paciente e executada no domicílio.

- O período de execução da técnica permite uma maior interação com o paciente, sendo possível realizar ações educativas.

- É importante ressaltar ainda a oportunidade de aprendizado que este trabalho proporciona frente à interação profissional que este tipo de assistência exige.

\section{AGRADECIMENTOS}

Agradecemos às Enfermeiras Paulete Cavasim Leandro e Ana Lúcia Pereira e à Auxiliar de Enfermagem Maria Betânia Torres do ARE pelo apoio no desenvolvimento do Programa e à aluna Elaine Sartorelli, pela disponibilidade de continuidade do mesmo enquanto bolsista de extensão.

ABSTRACT: This work has as a goal to contribute to decrease the inability in leprosy and continuous recurrence of plantar ulcers, through the use of a treatment method using papaine and actions of health education. This work has been done in a health centre with patients that presented plantar ulcers and agreed to participate in the proposed treatment. Analysing and comparing the obtained data before and after treatment, a greater adhesion of patients to this treatment, a quicker healing in relation to other methods used before and a greater interaction with the patient has been observed.

KEYWORDS: Leprosy - Plantar ulcers. 
ANEXO 1 - FICHA DE AVALIAÇÃO FUNCIONAL DO PÉ

$\mathrm{N}^{\circ}$ Prontuário

Data:

IDENTIFICAÇÃO:

Nome:

Estado Civil:

Sexo:

Idade:

Endereço:

Bairro:

Profissão:

Forma da doença:

Situação atual: \{em atuação:

$\{$ em alta:

\section{ANTECEDENTES:}

Tempo de aparecimento da úlcera:

Tratamento anterior específico:

Calçado: Tipo:

Adequado $(\mathrm{S} / \mathrm{N})$ :

Modificações em uso:

Qual(is)

\section{EXAME GERAL:}

Estado do membro:

Aspecto da úlcera:

Grau de incapacidade:

OBSERVAÇŐES:

EVOLUÇÃO: 
ANEXO 2 - FICHA DE AVALIAÇÃO FUNCIONAL DO PÉ

Nome:

$\mathrm{N}^{\circ}$ prontuário:

PADRÃO:
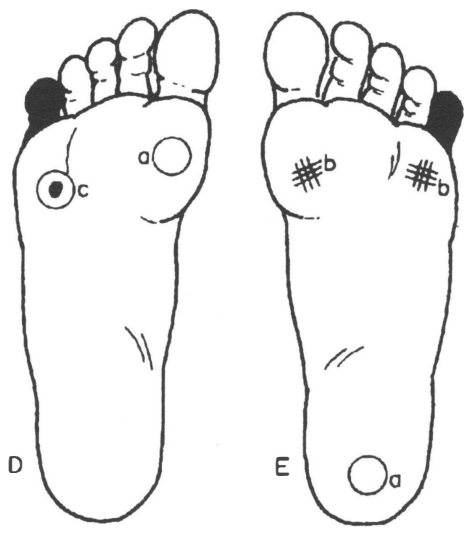

a) (círculo) - úlcera plantar

b) (traços paralelos) - calosidade

c) (traçado cheio com contorno) hematoma ou bolha

d) (área cheia, sem contorno) perda de tecido

CASO:
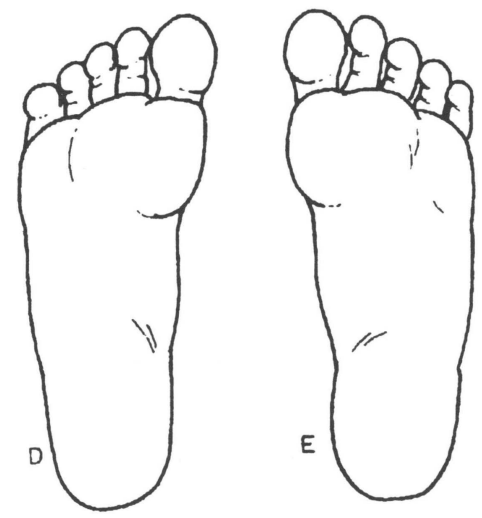

\section{REFERÊNCIAS BIBLIOGRÁFICAS}

1. ANSELMO, M.B.B. - Uso da papaína nos curativos de mal perfurante plantar. Escritório Regional de Saúde de São José do Rio Preto - SP. 1994. (mimeografado).

2. CRISTOFOLINI, Lúcia - Aspectos da Assistência de Enfermagem na hanseníase: Prevenção da úlcera plantar. FASC, Bauru, 1983

3. MONETTA,Lima - A importância da atuação do enfermeiro na execução dos curativos feitos com papaína, Revista Paulista de Enfermagem, São Paulo. v. 9, n.3, p. 83 - 87, Setembro/Dezembro, 1990.

4. TRINDADE, M.A.B e NEMES, M.I.B - Incapacidade físicas em hanseníase no momento do diagnóstico: características epidemiológicas dos casos registrados em 1983 a 1988 no Estado de São Paulo, Hansenologia Internationalis, v. 17, n.1-2, p. 8 - 14, 1992. 